\title{
Theories behind the effect of starch- and sucrose-reduced diets on gastrointestinal symptoms in irritable bowel syndrome (Review)
}

\author{
BODIL OHLSSON \\ Department of Internal Medicine, Lund University, Skåne University Hospital, 20502 Malmö, Sweden
}

Received July 1, 2021; Accepted July 22, 2021

DOI: $10.3892 / \mathrm{mmr} .2021 .12372$

\begin{abstract}
Increased amounts of starch and sugar have been added to the diet in the Western world during the last decades. Undigested carbohydrates lead to bacterial fermentation and gas production with diffusion of water, causing abdominal bloating, pain and diarrhea. Therefore, dietary advice is the first line of treatment of irritable bowel syndrome (IBS), a disease characterized by abdominal pain and altered bowel habits without any organic findings. Recently, a diet with a reduction of starch and sucrose led to a marked effect on gastrointestinal (GI) symptoms. The mechanism is unknown, but three possible mechanisms are presented in the present review. First, functional variants of the enzyme sucrase-isomaltase (SI) have been described in IBS. A subgroup of patients with IBS may thus suffer from partial SI deficiency with reduced digestion of starch and sucrose. Second, fructose absorption is less efficient than glucose absorption, which may lead to a physiological fructose malabsorption when ingesting high amounts of sucrose. A third mechanism is that high-sugar diets causing hyperglycemia, hyperinsulinemia and weight gain have led to painful neuropathy in animal models; whereas, improved metabolic control in humans has led to improvement of neuropathy. Starch- and sucrose-reduced diets lead to decreased levels of C-peptide, insulin, gastric inhibitory peptide, leptin and weight reduction. These metabolic changes may reduce the excitability of the hypersensitive nervous system often found in IBS and, thereby, lead to the reduced symptoms found after the diet. In conclusion, further studies are needed to investigate the pathophysiology behind development of symptoms after starch and sucrose intake, and the mechanisms behind symptom relief after reduced intake.
\end{abstract}

Correspondence to: Professor Bodil Ohlsson, Department of Internal Medicine, Lund University, Skåne University Hospital, 15 Jan Waldenström Street, Floor 5, 20502 Malmö, Sweden

E-mail: bodil.ohlsson@med.lu.se

Key words: fructose malabsorption, neuropathy, starch, sucrose, sucrase-isomaltase deficiency

\section{Contents}

1. Introduction

2. Genetic variants of sucrase-isomaltase deficiency

3. Monosaccharide absorption in the small intestine

4. Gastrointestinal effects of monosaccharide absorption

5. Effect of sugar-rich diets on the development of polyneuropathy

6. Discussion

\section{Introduction}

Gastrointestinal (GI) symptoms without any organic changes are called functional gastrointestinal disorders (FGID). The most common of these disorders is irritable bowel syndrome (IBS) (1). The pathophysiology behind FGID is unknown, but visceral hypersensitivity, psychological factors, low-grade inflammation, alterations in gut microbiota composition, or hormonal profile have been discussed (2).

IBS symptoms are frequently experienced during food intake, and as such, dietary interventions are usually prescribed to improve the symptoms (3). Also, patients with IBS have been found to have altered expression of endocrine cells in the GI tract and different levels of circulating hormones (4-6).

Dietary changes may influence the production of gut hormones since the production is predominantly influenced by food ingestion and food nutrient content (7). Hormones such as C-peptide, gastric inhibitory peptide (GIP), glucagon, glucagon-like peptide-1 (GLP-1), and insulin are key hormones in regulation of glucose homeostasis. These hormones control energy and glucose metabolism by acting on the function of the digestive system in glucose regulation, motility, and pancreatic function $(8,9)$. Leptin controls appetite and food intake, thereby regulating energy intake (10). Thus, the improvement of IBS symptoms with dietary changes may possibly be linked to the effect of changes in gut hormones (11).

The first line of dietary advice is the National Institute for Health and Care Excellence (NICE) guidelines, which recommend regular meal patterns and decreased intake of mineral water, caffeine, fat, and spicy foods (12), or the low FODMAP diet, which advocates exclusion of fermentable oligo-, di- and monosaccharides and polyols (13). These diets have an effect in $20-50 \%$ of IBS patients (14). 
Recently, a diet with starch and sucrose reduction (SSRD) has been shown to markedly reduce the GI symptoms in IBS patients with a response rate of $74 \%(15,16)$. The reduction in GI symptoms correlated with the reduction in intake of carbohydrates, disaccharides, starch, sucrose, and sugar (17). We found decreased levels of C-peptide, insulin, GIP, and leptin after introduction of the SSRD, but the hormonal changes only correlated with the decrease of carbohydrate intake and weight, not with the decrease of GI symptoms (18). Circulating levels of inflammatory factors were not affected by the diet (17). Although the dietary changes led to corresponding changes in feces microbiota, this was not correlated with the changes in GI symptoms (unpublished data).

The mechanisms behind the effect in IBS of SSRD is not determined, but three different theories are plausible explanations to GI symptoms after intake of starch and sucrose, i.e., sucrase-isomaltase (SI) deficiency, overloading of the physiological absorptive system, or food-induced dysfunction of the nervous system (Table I).

\section{Genetic variants of sucrase-isomaltase deficiency}

Sucrose, or saccharose, consists of one glucose and one fructose molecule. The bond between these two molecules is broken by the membrane-bound enzyme SI. The same enzyme also hydrolyzes the glucose molecules in the short oligosaccharides and starch (Fig. 1). This $\alpha$-glucosidase enzyme consists of two enzyme domains of the glycoside hydrolase family GH31, one serving as isomaltase, the other as sucrase (19). Severe congenital sucrase-isomaltase deficiency (CSID) is an autosomal recessive unusual condition with mutations of the SI gene on chromosome 3q25-26. Lack of the SI enzyme leads to impaired ability to hydrolyze sucrose, maltose, short glucose oligomers, and branched dextrins. More than 25 different mutations have been described (20). CSID was unknown among the indigenous people of Greenland as long as they lived on fish. After the introduction of the Western diet with a high proportion of sugar and starch in the latter half of the last century, the prevalence of CSID in Greenland has risen to between 5 and $10 \%$ (21). The prevalence of CSID varies but has been described as 5-10\% in Greenland, 3-7\% in Canada and 3\% in Alaska. The prevalence in North America and Europe varies between $1 / 500$ and 1/2,000 (22).

Functional variants appear to be more common in the population than CSID and can lead to similar maldigestion (22). These functional variants of this mutation have previously been described in high prevalence in IBS $(23,24)$. In addition to the degree of enzyme deficiency, the type of dietary intake also influences the efficiency of hydrolysis, since naturally phytochemicals can inhibit the enzyme activity (25).

Undigested sugars are fermented by the gut microbiota with ensuing gas production and water diffusion, which lead to symptoms in the form of abdominal tension, abdominal pain, and diarrhea (14). The classic CSID manifests itself during infancy when one begins to introduce fruits and juices into the diet and leads to severe diarrhea, poor weight gain, irritability, and diaper rash. The treatment mainly consists of avoiding starch and sucrose, which reverses the symptoms. Milder forms of mutations can present clinically later in life with the same symptoms as in other carbohydrate intolerances, especially diarrhea, and can be misdiagnosed as IBS in adults (26).

\section{Monosaccharide absorption in the small intestine}

Glucose, galactose, and fructose are the most common monosaccharides. The absorption of monosaccharides at the luminal brush border membrane (BBM) and transportation out of the cells at the basolateral membrane (BLM) are mediated by transport molecules. Glucose and galactose are absorbed at the BBM by sodium-glucose cotransporter 1 (SGLT1), driven by the $\mathrm{Na}^{+}$gradient, and by glucose transporter 2 (GLUT2), driven by diffusion. SGLT1 is the rate limiting transporter for glucose absorption (27). GLUT2 is mainly expressed in the BBM during presence of high luminal glucose concentrations, and not between the meals, when the glucose concentration is low. Glucose and galactose leave the cell at the BLM by GLUT2. Fructose is transported by GLUT5 both at the BBM and the BLM (Fig. 2) (28).

The absorptive capacity varies in nonspecific ways, e.g., depending on the absorptive surface, number of enterocytes, and their degree of differentiation. This slow adaption has been observed in response to changed nutritional supply, during diabetes, and after surgery $(29,30)$. Specific adaptions of monosaccharides are rapid and may occur within minutes or hours but may also develop during days. They include changes in the amount of transport molecules and are due to transcriptional and/or posttranscriptional regulations. They have been described following diurnal rhythm, after up-take of carbohydrate-rich meals, and in response to carbohydrate content, hormone levels, and neuronal activation (28). The capacity for glucose absorption peaks in the late light/early dark phase in rats during free access to food (31). This is consistent with the peaking of SGLT1 mRNA expression (32) and sucrase activity at the same time point (33). This may be considered physiologically since $90 \%$ of the ingestion in rodents are during the night (32). High glucose concentration in the small intestine leads to short-term upregulation of SGLT1 in human and rodents. Both glucagon, GLP, insulin, EGF, and prostaglandins upregulate SGLT1, whereas cholecystokinin (CCK) and leptin downregulate the transport molecule (28).

Several mechanisms are involved in the long-term regulation of SGLT1 and include both a direct effect of glucose, galactose, and fructose and an indirect effect through taste reception and hormonal changes. The effect is mainly exerted through translational and posttranslational levels, but also on mRNA level $(34,35)$.

The expression of GLUT2 is coordinated with the expression of SGLT1 regarding diurnal rhythm, glucose concentration in the small intestine, and hormonal effects (32). Specific food, such as strawberries and blueberries containing flavonoids and other phenolic compounds, downregulate both the transport and mRNA levels of SGLT1 and GLUT2 (36). The expression of GLUT5 is coordinated with the expression of SGLT1 and GLUT2 regarding diurnal rhythm and fructose intake (32). A great portion of the absorbed fructose is converted in the enterocytes to glucose through gluconeogenesis.

\section{Gastrointestinal effects of monosaccharide absorption}

Malfunction of monosaccharide transporters. Glucosegalactose malabsorption (GGM) is a rare congenital autosomal 
Table I. Possible explanations for gastrointestinal symptoms after starch and sucrose intake.

\begin{tabular}{|c|c|c|}
\hline Etiology & Possible mechanisms & Symptoms \\
\hline $\begin{array}{l}\text { Sucrase-isomaltase } \\
\text { deficiency }\end{array}$ & $\begin{array}{l}\text { Unabsorbed carbohydrates lead to fermentation, gas } \\
\text { production, water diffusion and distention }\end{array}$ & $\begin{array}{l}\text { Abdominal bloating, flatulence, pain and } \\
\text { diarrhea }\end{array}$ \\
\hline Fructose intolerance & $\begin{array}{l}\text { Unabsorbed carbohydrates lead to fermentation, } \\
\text { gas production, water diffusion and distention }\end{array}$ & $\begin{array}{l}\text { Abdominal bloating, flatulence, pain and } \\
\text { diarrhea }\end{array}$ \\
\hline $\begin{array}{l}\text { Endocrine and metabolic } \\
\text { effects in the tissue and } \\
\text { nerves }\end{array}$ & $\begin{array}{l}\text { Hyperinsulinemia, increased release of GIP and } \\
\text { GLP-1, dyslipidemia, oxidative stress, advanced } \\
\text { glycemic end products and other metabolic changes } \\
\text { affect the central and peripheral nerves with altered } \\
\text { motility and perception }\end{array}$ & $\begin{array}{l}\text { Abdominal bloating, pain, constipation } \\
\text { and diarrhea }\end{array}$ \\
\hline
\end{tabular}

GIP, gastric inhibitory peptide; GLP-1, glucagon-like peptide-1.

Sucrose

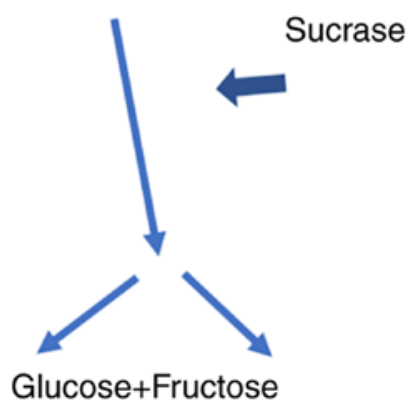

Starch

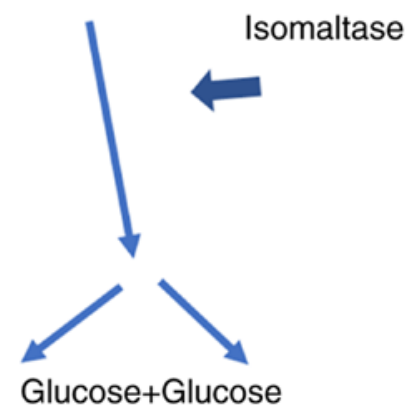

Figure 1. Digestion of sucrose and starch to monosaccharides by the enzymes sucrase and isomaltase in the intestinal brush border.

recessive disorder with severe diarrhea in newborn, depending on defect $\mathrm{Na}^{+}$-glucose cotransport in the small intestine (37). The therapy is removal of glucose and galactose from the diet. Malabsorption of glucose and galactose may also depend on mutations in gene encoding neurogen- 3 and leads to depletion of endocrine cells and cause general monosaccharide malabsorption (38). Fanconi-Bickel syndrome is another rare congenital disease with impaired absorption of glucose and galactose (39).

The dramatic increase of nutrients and beverages which are enriched with sucrose has led to higher amount of fructose in the food (40). In humans, the capacity of fructose absorption is much smaller than the glucose absorption (41). In a population of healthy adults, an intestinal load of $25 \mathrm{~g}$ fructose was only absorbed completely by one-half of the individuals (42). Isolated fructose intolerance due to defects in GLUT5, or overloading of the physiological capacity of fructose absorption, may be one reason to symptoms of abdominal pain, cramps, and diarrhea after ingestion of high amounts of fructose. This condition may be mistaken as FGID (43).

Effects of transport molecules on hormone secretion and local inflammation. Since SGLT1 is involved in membrane polarization, this includes activation of several $\mathrm{Ca}^{+}$channels, activation of PKC $\beta I I$, and phosphorylation of myosin II and MAP kinases, among several other proteins (28). An increased
SGLT1-mediated glucose transport may protect from lipopolysaccharide (LPS)-induced apoptosis (44). Further, SGLT1 influences the effects of cytotoxic drugs in the small intestine and seem to have the same protective effect regarding these drugs as concerning LPS $(44,45)$.

High luminal glucose concentrations involve SGLT1 and GLUT2 in the glucose-dependent stimulation of GLP-1 and GIP secretion, which also involves sweet taste receptors. A high intracellular glucose level increases carbohydrate metabolism, which lead to openings of $\mathrm{Ca}^{+}$channels and exocytosis of vesicles containing GLP-1 and GIP (27), hormones with effects on GI motility (9).

\section{Effect of sugar-rich diets on the development of poly- neuropathy}

The pathophysiology behind polyneuropathy is multifactorial and involves hyperglycemia and metabolic disturbances. The mechanisms involve oxidative stress, accumulation of advanced glycation end products, P13K/Akt signaling pathways, and chronic inflammation (46-49). Animal models with diets high of fat and/or sugar have been acknowledged for decades to study metabolic effects and their complications. A diet for 4 weeks with high sucrose intake to rats showed a progressive increase in blood glucose levels, insulin levels, and Homeostatic Model Assessment for 


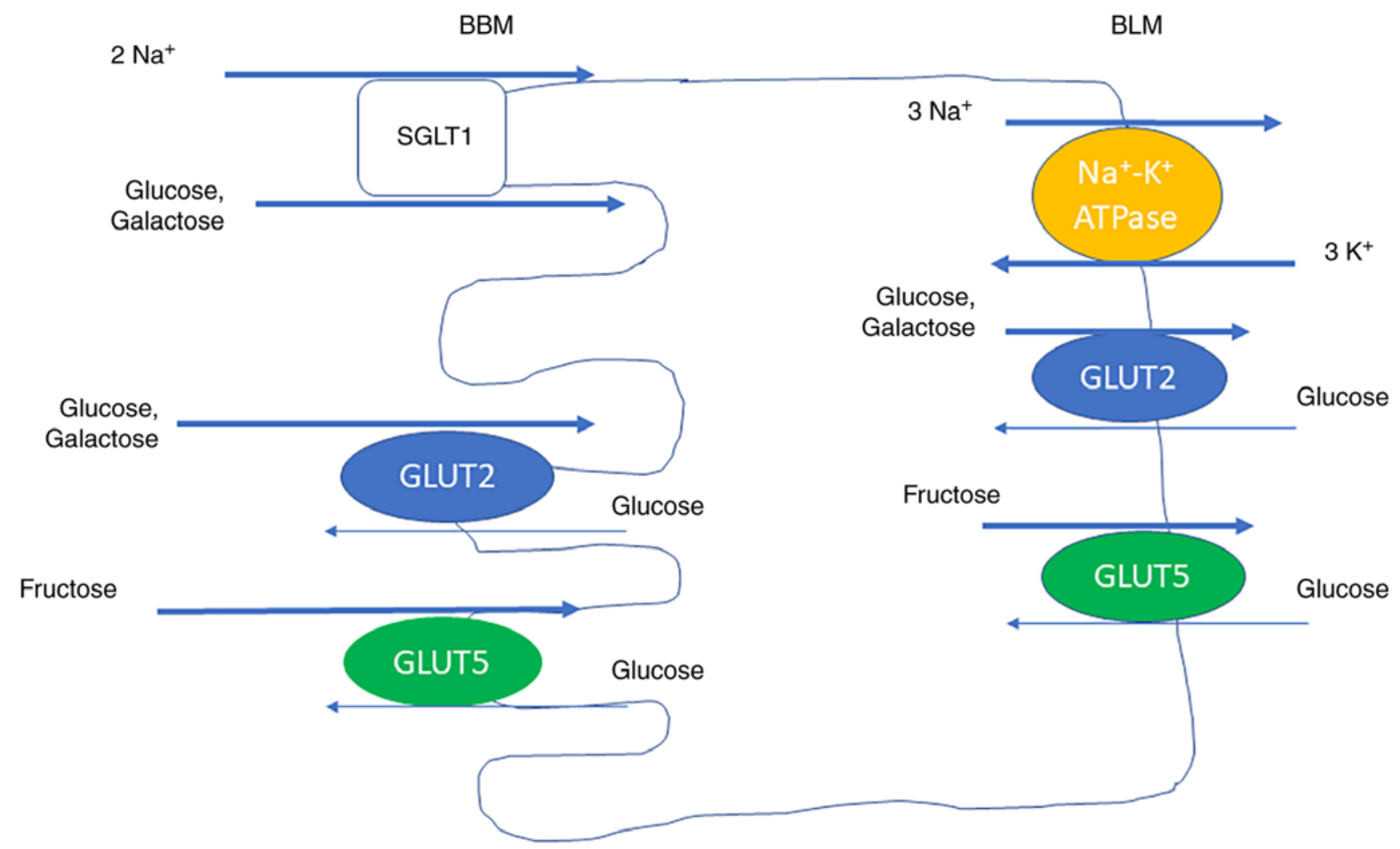

Figure 2. Mechanisms of monosaccharide absorption. Absorption of monosaccharides by enterocytes at the luminal BBM with SGLT1, GLUT2 and GLUT5, and transportation out of the cells at the BLM by GLUT2 and GLUT5. $\mathrm{Na}^{+}$and $\mathrm{K}^{+}$pumps (ATPase) drive the $\mathrm{Na}^{+}$gradient, enabling the absorption of glucose and galactose. Modified from ref. (28). SGLT1, sodium-glucose cotransporter 1; GLUT, glucose transporter; BLM, basolateral membrane; BBM, brush border membrane.

Insulin Resistance (HOMA-IR) (50). In similarity, a high fat-sucrose diet for 3 months led to increased fasting glucose levels after 25 days, although the levels were not defined as hyperglycemia. In parallel, the insulin levels, free fatty acid levels, and HOMA-IR were also elevated (51). Increased mechanical pain sensitivity was found $\sim 1$ month later (51), which indicates that the neuropathy may occur after chronic exposure to hyperinsulinemia, dyslipidemia, and impaired glucose tolerance, as has been suggested in humans (52-54). Histopathological examinations revealed myelin breakdown, axonal degeneration, and small fiber neuropathy in the periphery. Also, the spinal dorsal column was affected with loss of inter-fiber matrix and dramatic reduction of myelin and axonal degeneration (51). A cafeteria diet (CAD) including cakes, biscuits, meat pies, and potato chips for 3 months to rats led to increased body weight and increased glucose and insulin levels consistent with prediabetes. Although the nerve conduction tests were normal, a superexcitability was found in the tibial motor nerve (55). Excitability parameters are electrophysiological measure of axonal membrane and ion channels, and the finding of superexcitability indicates an early functional change in the peripheral axon (56). The superexcitability correlated with weight, insulin levels, HOMA-IR, and leptin levels (55), which suggest that metabolic changes may drive early axonal dysfunction.

In line with these animal studies, changes in motor excitability have been demonstrated in human prediabetes (57) and found prior to overt polyneuropathy (58). Improvement of the metabolic control leads to regression of painful neuropathy (59).

\section{Discussion}

During the last decades, the sugar intake has been markedly increased (40). The higher luminal sugar concentrations, the more upregulation of the enzymatic and absorptive systems, with higher glucose absorption consequently (28). Accordingly, the increased sugar consumption has several effects on the homeostasis and thereby on health (60). Decreased intake of starch and sucrose does not only influence the GI symptoms (17), it also leads to weight reductions and a less risk of metabolic syndromes (61). Since reduction of carbohydrates correlated with the reduction of GI symptoms (17), there must be a direct effect of the diet on the bowel. Although no changes in circulatory inflammatory factors were found (17), local inflammation in the GI tract may occur (62).

Elevated levels of C-peptide and hyperinsulinemia have been described in IBS $(63,64)$. Numerous patients with IBS also suffer from metabolic syndromes $(63,65)$. The lower values of C-peptide, insulin, GIP, and leptin and reduced weight after introduction of the SSRD may have several effects in the body (28). A healthier diet should probably improve not only the GI symptoms but also the general health status (66). The animal models described above stress the metabolic changes following high sugar intake with ensuing painful neuropathy $(50,51,55)$. Also, human studies stress the 
impact of hyperglycemia, hyperinsulinemia, and metabolic syndrome on neuropathy (52-54). As described in several publications, IBS is in most cases characterized by central and/or peripheral hypersensitivity (67). This hypersensitivity may explain the experience of pain in the absence of organic changes (1). Neural function tests are seldom performed in IBS patients, but dietary trials including neural function tests are warranted in IBS. The effect of SSRD also on the experience of extra-intestinal symptoms support the role of a general hypersensitivity in IBS, possible to reverse by a diet with reduced content of starch and sucrose (16).

There is a close relation between luminal and intracellular glucose concentrations, expression of glucose transporters, and the release of gut hormones $(28,34,35)$. The endocrine changes observed in IBS may be secondary to a diet with high contents of sugar $(16,18)$ and represent markers of disturbed metabolism $(18,28)$ and does not necessarily mean that the symptoms are related to the endocrine differences $(3,6,11)$. The balance between different hormonal systems may be of greater importance than the effect of single hormones. Further, local factors due to impaired metabolic control such as oxidative stress, accumulation of advanced glycation end products, and chronic low-grade inflammation may be of importance for pain perception and experience of different symptoms (46-49).

In the SSRD study, there was a correlation both between carbohydrates, disaccharides, starch, sucrose, and total sugar with the total burden of GI symptoms (17). Thus, not only fructose intolerance could explain the improvement after the diet. The GI symptoms may depend on SI deficiency in some cases and fructose intolerance in other cases. In the SSRD intervention, some IBS patients with functional variants did not have any effect of the diet, and some patients without variants had a prompt effect of the diet (data not shown). Although a few of the patients with functional variants of SI did not have any effect of SSRD, this may depend on poor compliance to the diet, and does not prove that the genetics is of no importance. The marked effect of SSRD in IBS patients without any functional variants point to several different mechanisms. An overloading of glucose has not been described in the literature, but fructose intolerance could be one possible hypothesis.

In addition to SGLT1, GLUT2, and GLUT5, several other monosaccharide transporters exist in the GI tract. The regulation of these transporters is extremely complex, and a number of more in-depth studies are needed in vitro as well as in vivo, to understand the interaction between food load, absorption, and GI symptoms. The overconsumption of carbohydrate-rich food in the society requires that we learn more about these mechanisms to improve health and diminish the risk of metabolic syndrome and GI symptoms (68).

\section{Acknowledgements}

Not applicable.

\section{Funding}

The study was funded by the Development Foundation of Region Skåne (grant nos. REGSKANE-818781 and 2018-Projekt0024).

\section{Availability of data and materials}

Not applicable.

\section{Authors' contributions}

BO has reviewed the literature, written the manuscript and created the figures. The author has read and approved the final manuscript. Data sharing is not applicable.

\section{Ethics approval and consent to participate}

Not applicable.

\section{Patient consent for publication}

Not applicable.

\section{Competing interests}

The author declares that they have no competing interests.

\section{References}

1. Lacy BE, Mearin F, Chang L, Chey WD, Lembo AJ, Simren M and Spiller R: Bowel Disorders. Gastroenterology 150: P1393-P1407.E5, 2016.

2. Black CJ and Ford AC: Global burden of irritable bowel syndrome: Trends, predictions and risk factors. Nat Rev Gastroenterol Hepatol 17: 473-486, 2020.

3. El-Salhy M, Ostgaard H, Gundersen D, Hatlebakk JG and Hausken T: The role of diet in the pathogenesis and management of irritable bowel syndrome (review). Int J Mol Med 29: 723-731, 2012.

4. Besterman HS, Sarson DL, Rambaud JC, Stewart JS, Guerin S and Bloom SR: Gut hormone responses in the irritable bowel syndrome. Digestion 21: 219-224, 1981.

5. Semnani S, Roshandel G, Keshtkar A, Najafi L, Amiriani T, Farajollahi M, Moradi A and Joshaghani H: Serum leptin levels and irritable bowel syndrome: A new hypothesis. J Clin Gastroenterol 43: 826-830, 2009.

6. El-Salhy M, Hatlebakk JG, Gilja $\mathrm{OH}$ and Hausken T: Irritable bowel syndrome: Recent developments in diagnosis, pathophysiology, and treatment. Expert Rev Gastroenterol Hepatol 8: 435-443, 2014.

7. Cummings DE and Overduin J: Gastrointestinal regulation of food intake. J Clin Invest 117: 13-23, 2007.

8. Wahren J, Ekberg K, Johansson J, Henriksson M, Pramanik A Johansson BL, Rigler R and Jörnvall H: Role of C-peptide in human physiology. Am J Physiol Metab 278: E759-E768, 2000.

9. Drucker DJ: The role of gut hormones in glucose homeostasis. J Clin Invest 117: 24-32, 2007.

10. Al-Suhaimi EA and Shehzad A: Leptin, resistin and visfatin: The missing link between endocrine metabolic disorders and immunity. Eur J Med Res 18: 12, 2013.

11. El-Salhy M, Gilja OH, Gundersen D, Hatlebakk JG and Hausken T: Interaction between ingested nutrients and gut endocrine cells in patients with irritable bowel syndrome (review). Int J Mol Med 34: 363-371, 2014.

12. McKenzie YA, Bowyer RK, Leach H, Gulia P, Horobin J, O'Sullivan NA, Pettitt C, Reeves LB, Seamark L, Williams M, et al: British dietetic association systematic review and evidence-based practice guidelines for the dietary management of irritable bowel syndrome in adults (2016 update). J Hum Nutr Diet 29: 549-575, 2016.

13. Algera J, Colomier E and Simrén M: The dietary management of patients with irritable bowel syndrome: A narrative review of the existing and emerging evidence. Nutrients 11: 2162, 2019.

14. Mitchell H, Porter J, Gibson PR, Barrett J and Garg M: Review article: Implementation of a diet low in FODMAPs for patients with irritable bowel syndrome-directions for future research. Aliment Pharmacol Ther 49: 124-139, 2019. 
15. Nilholm C, Larsson E, Roth B, Gustafsson R and Ohlsson B: Irregular dietary habits with a high intake of cereals and sweets are associated with more severe gastrointestinal symptoms in IBS patients. Nutrients 11: 1279, 2019.

16. Nilholm C, Roth B and Ohlsson B: A dietary intervention with reduction of starch and sucrose leads to reduced gastrointestinal and extra-intestinal symptoms in IBS patients. Nutrients 11: 1662, 2019.

17. Nilholm C, Larsson E, Sonestedt E, Roth B and Ohlsson B: Assessment of a 4-week starch- and sucrose-reduced diet and its effects on gastrointestinal symptoms and inflammatory parameters among patients with irritable bowel syndrome. Nutrients 13: 416, 2021.

18. Saidi K, Nilholm C, Roth B and Ohlsson B: A carbohydraterestricted diet for patients with irritable bowel syndrome lowers serum C-peptide, insulin, and leptin without any correlation with symptom reduction. Nutr Res 86: 23-36, 2021.

19. Rose DR, Chaudet MM and Jones K: Structural studies of the intestinal $\alpha$-glucosidases, maltase-glucoamylase and sucrase-isomaltase. J Pediatr Gastroenterol Nutr 66 (Suppl 3): S11-S13, 2018.

20. Treem WR: Congenital sucrase-isomaltase deficiency. J Pediatr Gastroenterol Nutr 21: 1-14, 1995.

21. Gudmand-Høyer E, Fenger HJ, Kern-Hansen P and Madsen PR Sucrase deficiency in Greenland. Incidence and genetic aspects Scand J Gastroentreol 22: 24-28, 1987.

22. Treem WR: Clinical aspects and treatment of congenital sucrase-isomaltase deficiency. J Pediatr Gastroenterol Nutr 55 (Suppl 2): S7-S13, 2012

23. Garcia-Etxebarria K, Zheng T, Bonfiglio F, Bujanda L, Dlugosz A, Lindberg G, Schmidt PT, Karling P, Ohlsson B, Simren M, et al: Increased prevalence of rare sucrase-isomaltase pathogenic variants in irritable bowel syndrome patients. Clin Gastroenterol Hepatol 16: 1673-1676, 2018.

24. Henström M, Diekmann L, Bonfiglio F, Hadizadeh F, Kuech EM Von Köckritz-Blickwede M, Thingholm LB, Zheng T, Assadi G, Dierks C, et al: Functional variants in the sucrase-isomaltase gene associate with increased risk of irritable bowel syndrome. Gut 67: 263-270, 2018.

25. Tundis R, Loizzo MR and Menichini F: Natural products as alpha-amylase and alpha-glucosidase inhibitors and their hypoglycaemic potential in the treatment of diabetes: An update. Mini Rev Med Chem 10: 315-331, 2010.

26. Kim SB, Calmet FH, Garrido J, Garcia-Buitrago MT and Moshiree B: Sucrase-isomaltase deficiency as a potential masquerader in irritable bowel syndrome. Dig Dis Sci 65: 534-540, 2020.

27. Gorboulev V, Schürmann A, Vallon V, Kipp H, Jaschke A Klessen D, Friedrich A, Scherneck S, Rieg T, Cunard R, et al $\mathrm{Na}(+)$-D-glucose cotransporter SGLT1 is pivotal for intestinal glucose absorption and glucose-dependent incretin secretion. Diabetes 61: 187-196, 2012.

28. Koepsell H: Glucose transporters in the small intestine in health and disease. Pflugers Arch 472: 1207-1248, 2020.

29. Smith MW, Peacock MA and James PS: Galactose increases microvillus development in mouse jejunal enterocytes. Comp Biochem Physiol A Comp Physiol 100: 489-493, 1991.

30. Lorenz-Meyer H, Thiel F, Menge H, Gottesbüren H and Riecken EO: Structural and functional studies on the transformation of the intestinal mucosa in rats with experimental diabetes. Res Exp Med (Berl) 170: 89-99, 1977.

31. Stevenson NR, Ferrigni F, Parnicky K, Day S and Fierstein JS Effect of changes in feeding schedule on the diurnal rhythms and daily activity levels of intestinal brush border enzymes and transport systems. Biochim Biophys Acta 406: 131-145, 1975.

32. Iwashina I, Mochizuki K, Inamochi Y and Goda T: Clock genes regulate the feeding schedule-dependent diurnal rhythm changes in hexose transporter gene expressions through the binding of BMAL1 to the promoter/enhancer and transcribed regions. J Nutr Biochem 22: 334-343, 2011.

33. Hara $\mathrm{E}$ and Saito M: Diurnal change in digestion and absorption of sucrose in vivo in rats. J Nutr Sci Vitaminol (Tokyo) 35 667-671, 1989

34. Miyamoto K, Hase K, Takagi T, Fujii T, Taketani Y, Minami H Oka T and Nakabou Y: Differential responses of intestinal glucose transporter mRNA transcripts to levels of dietary sugars Biochem J 295: 211-215, 1993.

35. Margolskee RF, Dyer J, Kokrashvili Z, Salmon KS Ilegems E, Daly K, Maillet EL, Ninomiya Y, Mosinger B and Shirazi-Beechey SP: T1R3 and gustducin in gut sense sugars to regulate expression of $\mathrm{Na}^{+}$-glucose cotransporter 1 . Proc Natl Acad Sci USA 104: 15075-15080, 2007.
36. Pereira DF, Cazarolli LH, Lavado C, Mengatto V, Figueiredo MS, Guedes A, Pizzolatti MG and Silva FR: Effects of flavonoids on $\alpha$-glucosidase activity: Potential targets for glucose homeostasis. Nutrition 27: 1161-1167, 2011.

37. Lindquist B and Meeuwisse GW: Chronic diarrhoea caused by monosaccharide malabsorption. Acta Paediatr 51: 674-685, 1962

38. Wang J, Cortina G, Wu SV, Tran R, Cho JH, Tsai MJ, Bailey TJ, Jamrich M, Ament ME, Treem WR, et al: Mutant neurogenin-3 in congenital malabsorptive diarrhea. N Engl J Med 355: 270-280, 2006.

39. Santer R, Schneppenheim R, Suter D, Schaub J and Steinmann B: Fanconi-Bickel syndrome-the original patient and his natural history, historical steps leading to the primary defect, and a review of the literature. Eur J Pediatr 157: 783-797, 1998.

40. Tsan L, Décarie-Spain L, Noble EE and Kanoski SE: Western diet consumption during development: setting the stage for neurocognitive dysfunction. Front Neurosci 15: 632312, 2021

41. Douard V and Ferraris RP: Regulation of the fructose transporter GLUT5 in health and disease. Am J Physiol Endocrinol Metab 295: E227-E237, 2008

42. Skoog SM and Bharucha AE: Dietary fructose and gastrointestinal symptoms: A review. Am J Gastroenterol 99: 2046-2050, 2004.

43. Wasserman D, Hoekstra JH, Tolia V, Taylor CJ, Kirschner BS, Takeda J, Bell GI, Taub R and Rand EB: Molecular analysis of the fructose transporter gene (GLUT5) in isolated fructose malabsorption. J Clin Invest 98: 2398-2402, 1996.

44. Yu LC, Turner JR and Buret AG: LPS/CD14 activation triggers SGLT-1-mediated glucose uptake and cell rescue in intestinal epithelial cells via early apoptotic signals upstream of caspase-3. Exp Cell Res 312: 3276-3286, 2006.

45. Ikari A, Nagatani Y, Tsukimoto M, Harada H, Miwa M and Takagi K: Sodium-dependent glucose transporter reduces peroxynitrite and cell injury caused by cisplatin in renal tubular epithelial cells. Biochim Biophys Acta 1717: 109-117, 2005.

46. Vincent AM, Hayes JM, McLean LL, Vivekanandan-Giri A, Pennathur S and Feldman EL: Dyslipidemia-induced neuropathy in mice: The role of oxLDL/LOX-1. Diabetes 58: 2376-2385, 2009.

47. Kim B and Feldman EL: Insulin resistance in the nervous system. Trends Endocrinol Metabol 23: 133-141, 2012.

48. Callaghan B and Feldman E: The metabolic syndrome and neuropathy: Therapeutic challenges and opportunities. Ann Neurol 74: 397-403, 2013

49. Preguiça I, Alves A, Nunes S, Gomes P, Fernandes R, Viana SD and Reis F: Diet-induced rodent models of diabetic peripheral neuropathy, retinopathy and nephropathy. Nutrients 12: 250, 2020.

50. Pranprawit A, Wolber FM, Heyes JA, Molan AL and Kruger MC Short-term and long-term effects of excessive consumption of saturated fats and/or sucrose on metabolic variables in sprague dawley rats: A pilot study. J Sci Food Agric 93: 3191-3197, 2013.

51. Xie F, Fu H, Hou JF, Jiao K, Costigan M and Chen J: High energy diets-induced metabolic and prediabetic painful polyneuropathy in rats. PLoS One 8: e57427, 2013.

52. Smith AG, Rose K and Singleton JR: Idiopathic neuropathy patients are at high risk for metabolic syndrome. J Neurol Sci 273: 25-28, 2008.

53. Calcutt NA, Cooper ME, Kern TS and Schmidt AM: Therapies for hyperglycaemia-induced diabetic complications: From animal models to clinical trials. Nat Rev Drug Discov 8: 417-429, 2009.

54. Smith AG: Impaired glucose tolerance and metabolic syndrome in idiopathic neuropathy. J Peripher Nerv Syst 17 (Suppl 2): S15-S21, 2012

55. Hossain MJ, Kendig MD, Wild BM, Issar T, Krishnan AV, Morris MJ and Arnold R: Evidence of altered peripheral nerve function in a rodent model of diet-induced prediabetes. Biomedicines 8: 313, 2020.

56. Bostock H, Cirkurel K and Burke D: Threshold tracking techniques in the study of human peripheral nerve. Muscle Nerve 21 137-158, 1998

57. Lin YC, Lin CS, Chang TS, Lee JE, Tani J, Chen HJ and Sung JY: Early sensory neurophysiological changes in prediabetes. J Diabetes Investig 11: 458-465, 2020.

58. Sung JY, Tani J, Chang TS and Lin CS: Uncovering sensory axonal dysfunction in asymptomatic type 2 diabetic neuropathy. PLoS One 12: e171223, 2017

59. Callaghan BC, Cheng HT, Stables CL, Smith SL and Feldman EL: Diabetic neuropathy: Clinical manifestations and current treatments. Lancet Neurol 11: 521-534, 2012. 
60. Ramne S, Drake I, Ericson U, Nilsson J, Orho-Melander M Engström $\mathrm{G}$ and Sonestedt E: Identification of inflammatory and disease-associated plasma proteins that associate with intake of added sugar and sugar-sweetened beverages and their role in type 2 diabetes risk. Nutrients 12: 3129, 2020.

61. Darwiche G,Höglund P, Roth B,Larsson E, Sjöberg T, Wohlfart B, Steen $S$ and Ohlsson B: An okinawan-based nordic diet improves anthropometry, metabolic control, and health-related quality of life in scandinavian patients with type 2 diabetes: A pilot trial. Food Nutr Res 60: 32594, 2016.

62. Della Corte KW, Perrar I, Penczynski KJ, Schwingshackl L, Herder C and Buyken AE: Effect of dietary sugar intake on biomarkers of subclinical inflammation: A systematic review and meta-analysis of intervention studies. Nutrients 10: 606, 2018.

63. Eriksson EM, Andrén KI, Eriksson HT and Kurlberg GK Irritable bowel syndrome subtypes differ in body awareness, psychological symptoms and biochemical stress markers. World J Gastroenterol 14: 4889-4896, 2008.

64. Mazur M, Furgała A, Jabłoński K, Mach T and Thor P: Autonomic nervous system activity in constipation-predominant irritable bowel syndrome patients. Med Sci Monit 18: CR493-CR499, 2012.
65. Gulcan E, Taser F, Toker A, Korkmaz U and Alcelik A: Increased frequency of prediabetes in patients with irritable bowel syndrome. Am J Med Sci 338: 116-119, 2009.

66. Roberts CK, Hevener AL and Barnard RJ: Metabolic syndrome and insulin resistance: Underlying causes and modification by exercise training. Compr Physiol 3: 1-58, 2013.

67. Camilleri M and Boeckxstaens G: Dietary and pharmacological treatment of abdominal pain in IBS. Gut 66: 966-974, 2017.

68. Grundy SM, Cleeman JI, Daniels SR, Donato KA, Eckel RH, Franklin BA, Gordon DJ, Krauss RM, Savage PJ, Smith SC Jr, et al: Diagnosis and management of the metabolic syndrome: An American heart association/national heart, lung, and blood institute scientific statement. Circulation 112: 2735-2752, 2005.

This work is licensed under a Creative Commons

Attribution-NonCommercial-NoDerivatives 4.0 International (CC BY-NC-ND 4.0) License. 